\title{
Effects of siRNA-mediated Cdc2 silencing on MG63 cell proliferation and apoptosis
}

\author{
XIANG-YONG QUE ${ }^{1}, \mathrm{YI} \mathrm{LI}^{1}, \mathrm{YU} \mathrm{HAN}^{2}$ and XIN-ZHI LI ${ }^{1}$ \\ ${ }^{1}$ Department of Orthopedics, Renhe Hospital of Three Gorges University, Yichang 443001; \\ ${ }^{2}$ Institute of Molecular Biology, Medical College, Three Gorges University, Yichang 443002, P.R. China
}

Received August 7, 2012; Accepted November 12, 2012

DOI: $10.3892 / \mathrm{mmr} .2012 .1209$

\begin{abstract}
The present study aimed to determine the effect of small interfering RNA (siRNA)-induced inhibition of cyclin-dependent kinase 2 (Cdc2) expression on osteosarcoma MG63 cell proliferation and apoptosis. An siRNA expression plasmid, psilencer $2.1-\mathrm{U} 6 / \mathrm{Cdc} 2$, targeting the $\mathrm{Cdc} 2$ gene, and a control psilencer 2.1-U6/Scramble plasmid were constructed and transfected into MG63 cells using liposomes. Cdc2 expression in the MG63 cells was investigated by western blot analysis and real-time polymerase chain reaction. Cell morphology was also examined. The effects of psilencer 2.1-U6/Cdc2 on MG63 cell proliferation and the cell cycle were detected via MTT and flow cytometry, respectively. Expression levels of apoptosis-related molecules, B-cell lymphoma 2 (Bcl-2) and Bcl-2-associated X (Bax) were determined by western blot analysis. MG63 cells stably transfected with the psilencer 2.1-U6/Cdc2 plasmid (MG63-siRNA/Cdc2) and negative control cells, MG63-siRNA/Scramble, were successfully obtained. The silencing efficiencies of the Cdc2-expressing mRNA and protein in MG63-siRNA/Cdc2 were 86 and $89 \%$ of that of the control MG63-siRNA/ Scramble cells, respectively. Interference of $\mathrm{Cdc} 2$ expression inhibited MG63 cell proliferation and was demonstrated to significantly increase and decrease cells in the $G_{2} / M$ and $S$ phases, respectively. Cdc2 expression silencing had negligible effects on Bcl-2 and Bax expression in MG63 cells. In conclusion, silencing of $\mathrm{Cdc} 2$ expression suppresses proliferation of osteosarcoma MG63 cells but has negligible effects on apoptosis.
\end{abstract}

\section{Introduction}

Osteosarcoma is one of the most common primary malignant tumour observed in children and adolescents, with a current

Correspondence to: Professor Xin-Zhi Li, Department of Orthopedics, Renhe Hospital of Three Gorges University, No. 410 Yi-Ling Street, Yichang 443001, P.R. China

E-mail: xyxzcn@126.com

Key words: osteosarcoma MG63 cells, siRNA, Cdc2, proliferation, apoptosis annual incidence rate of 3/1,000,000 (1). At present, combined neoadjuvant chemotherapy and surgery are mainly used to treat osteosarcoma, however, patient survival rates remain low (2). Studies of potential gene therapy candidates for the treatment of osteosarcoma have increased with the development of molecular biology and genomic sciences $(3,4)$. In previous studies $(5,6)$, we utilised a limiting dilution to obtain an osteosarcoma MG63 monoclonal cell substrain. Cell electrophoresis and invasion assays were then used to identify MG63 monoclonal cell substrains with variations in transfer and malignant characteristics. A cell substrain with high transfer and malignant characteristics (M8) and another with low transfer and malignant characteristics (M6) were verified by tumour transfer experiments in vitro. A gene chip was then used to scan and compare M8 with M6. Cyclin-dependent kinase 2 (Cdc2) expression in M8 was high at 2.67. Following this, quantitative reverse-transcription polymerase chain reaction (qRT-PCR) was utilised to verify the increase in gene expression of Cdc2 in M8 compared with M6 cells $(5,6)$ and $\mathrm{Cdc} 2$ was identified as a key gene for the proliferation and apoptosis of osteosarcoma MG63 cells. In addition, silencing of $\mathrm{Cdc} 2$ expression was demonstrated to inhibit proliferation and promote apoptosis of osteosarcoma MG63 cells. To verify these findings, a small interfering RNA (siRNA) expression plasmid targeting the $\mathrm{Cdc} 2$ gene was constructed in the current study and the effect of siRNA interference of Cdc2 expression on the proliferation and apoptosis of osteosarcoma MG63 cells was investigated. The results obtained may serve as an experimental basis for gene therapy of osteosarcoma.

\section{Materials and methods}

Cell culture. MG63 cells were grown in RPMI-1640 medium supplemented with $10 \%$ calf serum, $100 \mu \mathrm{g} / \mathrm{ml}$ streptomycin and $100 \mathrm{U} / \mathrm{ml}$ penicillin in a humidified $5 \% \mathrm{CO}_{2}$ and $95 \%$ air incubator at $37^{\circ} \mathrm{C}$.

Plasmid construction. The genetic code sequence for Cdc2 was obtained from GenBank (NM_001170406) in accordance with the principles of siRNA design. One siRNA-2 interference sequence was designed by Invitrogen Life Technologies (Carlsbad, CA, USA). An additional siRNA-1 interference sequence that was previously reported to be more effective (7) than that in the human genome was identified only as a Cdc2 
Table I. Template sequence of Cdc2 siRNA.

\begin{tabular}{ll}
\hline siRNA & Sequence (5'-3') \\
\hline $\begin{array}{l}\text { Negative } \\
\text { siRNA-Scramble } \\
\text { Forward }\end{array}$ & GATCCACTACCGTTGTTATAGGTGTTCAAGAGACACCTATAACAACGGTAGTTTTTTGGAAA \\
Reverse & AGCTTTTCCAAAAAACTACCGTTGTTATAGGTGTCTCTTGAACACCTATAACAACGGTAGG \\
Cdc2 siRNA-1 & \\
$\begin{array}{l}\text { Forward } \\
\text { Reverse }\end{array}$ & GATCCGGGGTTCCTAGTACTGCAATTCAAGAGATTGCAGTACTAGGAACCCCTTTTTTGGAAA \\
Cdc2 siRNA-2 & AGCTTTCCAAAAAAGGGGTTCCTAGTACTGCAATCTCTTGAATTGCAGTACTAGGAACCCCG \\
Forward & GATCCGTTGATCAACTCTTCAGGATTTCAAGAGAATCCTGAAGAGTTGATCAATTTTTTGGAAA \\
Reverse & AGCTTTTCCAAAAAATTGATCAACTCTTCAGGATTCTCTTGAAATCCTGAAGAGTTGATCAACG
\end{tabular}

Cdc2, cyclin-dependent kinase 2; siRNA, small interfering RNA.

gene interference sequence. A non-specific siRNA-scrambled (siRNA-Scramble) sequence, designed in a similar manner to serve as the negative control, was obtained from the Institute of Molecular Biology of (Three Gorges University; Table I). The three synthesised siRNA sequences were annealed using sticky ends and Bam HI and HindIII digestion and then connected to a psilencer 2.1-U6 that had been cut by the same enzyme. The three restructured psilencer 2.1/siRNA plasmids were then transformed into Escherichia coli DH5, screened for ampicillin resistance on an agar plate and then amplified in culture. Following this, plasmids were selected and sequenced.

Transient transfection. One day prior to transient transfection, the cells were plated in six-well plates at a concentration of $2 \times 10^{5}$ cells/well. When the cell density reached $\sim 80 \%$, transfection was performed using Lipofectamine ${ }^{\mathrm{TM}} 2000$ in accordance with the manufacturer's instructions. Following transfection $(\sim 24 \mathrm{~h})$, the proteins were extracted from the cells. Western blot analysis was then performed to determine the siRNA silencing efficiency.

Stable transfection. MG63 cells were plated in six-well plates at a concentration of $2 \times 10^{5}$ cells/well and then cultured in a conventional culture medium, as previously described. Cells were transfected the following day according to the manufacturer's instructions. In brief, diluted DNA and Lipofectamine $^{\mathrm{TM}} 2000$ complexes (total volume, $25 \mathrm{ml}$ ) were prepared and added to each MG63 cell-containing well. Cells were then incubated for 4-6 h. Post-transfection ( $48 \mathrm{~h})$, cells were incubated with $100 \mu \mathrm{g} / \mathrm{ml}$ hygromycin in RPMI-1640 medium with $10 \%$ calf serum for three weeks. Single clones with low Cdc2 expression were then identified via RT-PCR, western blot analysis and cell immunofluorescence.

Quantitative PCR. RNA from the cell lines was extracted using TRIzol reagent. cDNA was synthesised using SuperScript ${ }^{\mathrm{TM}}$ II Reverse Transcriptase according to the manufacturer's instructions. The primers used for amplification were as follows: $\mathrm{Cdc} 2$, 5'-TACCTATGGAGTTGTGTATAA-3' and 5'-ATTCCA CTTCTGGCCACACTT-3'; $\beta$-actin, 5'-CCACAGCTGAG
AGGGAAATC-3' and 5'-ATCCTCTTCCTCCCTGGAGA-3'. PCR cycling conditions were as follows: $94^{\circ} \mathrm{C}$ for $5 \mathrm{~min}$, 25 cycles at $94^{\circ} \mathrm{C}$ for $30 \mathrm{sec}, 55^{\circ} \mathrm{C}$ for $30 \mathrm{sec}, 72^{\circ} \mathrm{C}$ for $30 \mathrm{sec}$ and $78^{\circ} \mathrm{C}$ for $1 \mathrm{sec}$ for plate reading and $72^{\circ} \mathrm{C}$ for $5 \mathrm{~min}$. PCR products were separated via electrophoresis at $100 \mathrm{~V}$ for $30 \mathrm{~min}$ on a $1 \%$ agarose gel and then detected using ethidium bromide staining. The expected sizes of specific PCR products were verified using a 1-kb DNA reference ladder.

Western blot analysis. Cell lysates were prepared from six cloning strains. Normal MG63 and negative control cells were cultured for $24 \mathrm{~h}$. Protein samples were subjected to $12 \%$ sodium dodecyl sulphate-polyacrylamide gel electrophoresis and then transferred onto polyvinylidene fluoride membranes. Following blocking with 5\% non-fat dry milk in a Tris-buffered saline Tween-20 buffer for $1 \mathrm{~h}$, the samples were probed with a primary antibody against $\mathrm{Cdc} 2$ and a horseradish peroxidase-conjugated secondary antibody (Santa Cruz Biotechnology, Inc., Santa Cruz, CA, USA). Protein bands were detected using an enhanced chemiluminescence detection system and X-ray film exposure (Kodak, Rochester, NY, USA). $\beta$-actin was used as a loading control.

Cell immunofluorescence. MG63 and MG63-siRNA-Cdc2 cells were seeded into 24 -well culture plates. When the growth density reached $60 \%$, cells were fixed with ice-cold $4 \%$ paraformaldehyde and incubated with $10 \%(\mathrm{v} / \mathrm{v})$ goat serum as a blocking background. Following overnight incubation with the primary antibody against $\mathrm{Cdc} 2$, the cells were washed three times with phosphate-buffered saline (PBS) and then incubated with rhodamine-123-labeled anti-rabbit IgG for $1 \mathrm{~h}$ at $37^{\circ} \mathrm{C}$. The cells were washed three times with PBS and then examined via fluorescence/phase-contrast microscopy (TE2000S; Nikon, Tokyo, Japan).

Assay of cellular proliferation.MG63,MG63-siRNA/Scramble and MG63-siRNA/Cdc2 cells were seeded into 96-well culture plates (2,000 cells/well in $100 \mu 1$ RPMI-1640 medium). Culture medium was removed following culture for $0,24,48,72$ and 96 h. A $200 \mu \mathrm{l}$ MTT solution (0.25 g/l in RPMI-1640 medium) 

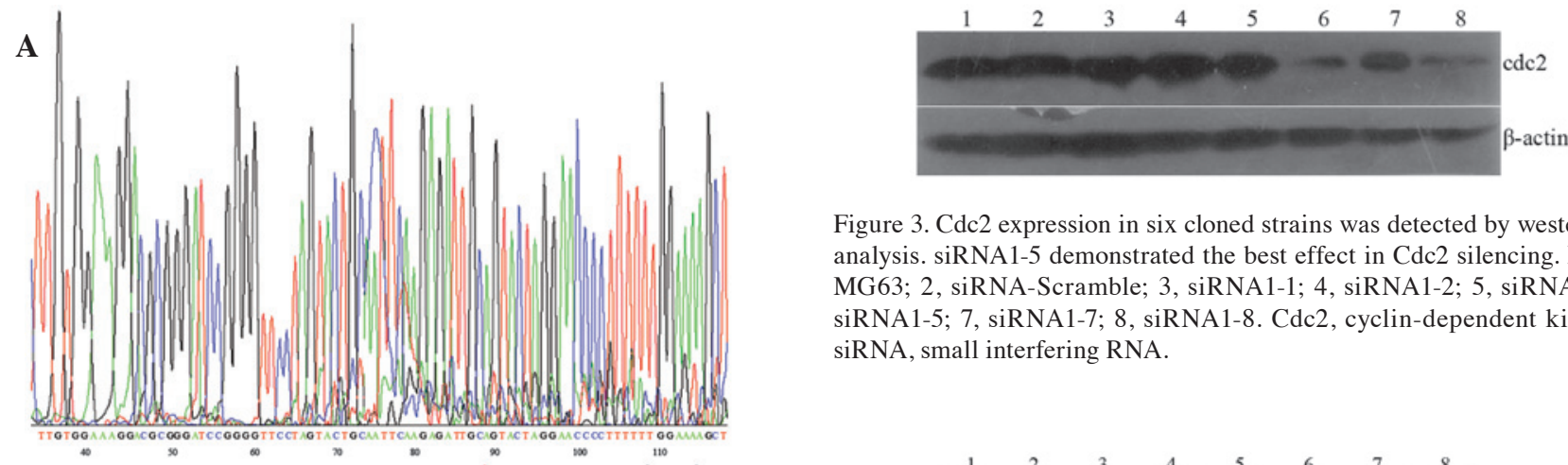

Figure 3. Cdc2 expression in six cloned strains was detected by western blot analysis. siRNA1-5 demonstrated the best effect in Cdc2 silencing. Lane 1, MG63; 2, siRNA-Scramble; 3, siRNA1-1; 4, siRNA1-2; 5, siRNA1-3; 6, siRNA1-5; 7, siRNA1-7; 8, siRNA1-8. Cdc2, cyclin-dependent kinase 2; siRNA, small interfering RNA.

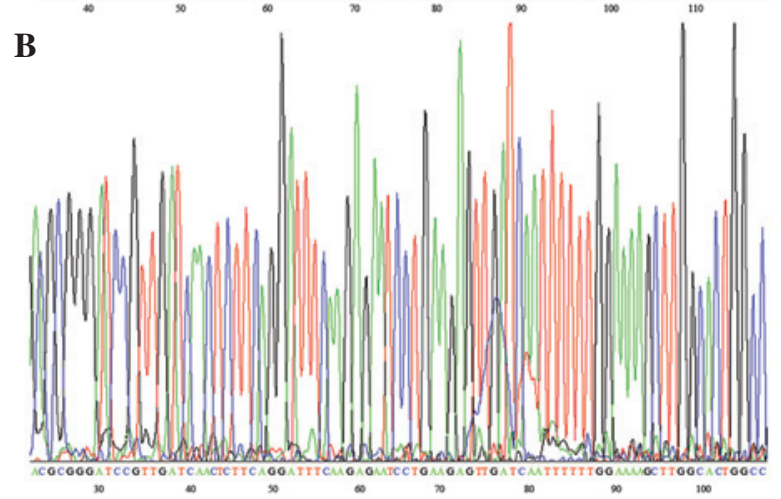

Figure 1. DNA sequencing assay of siRNA plasmids. (A) Insert DNA fragment in plasmid psilencer 2.1/siRNA-1. (B) Insert DNA fragment in plasmid psilencer2.1/siRNA-2. siRNA, small interfering RNA.

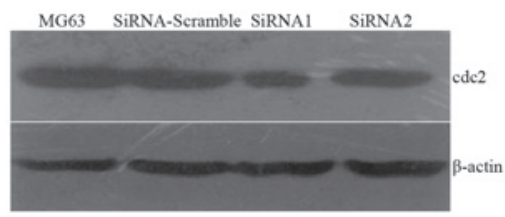

Figure 2. Western blot analysis of three siRNAs designed against Cdc2 to determine silencing efficiency following transient transfection. $\mathrm{Cdc} 2$, cyclin-dependent kinase 2; siRNA, small interfering RNA.

was added to each well and the cells were incubated at $37^{\circ} \mathrm{C}$ for $4 \mathrm{~h}$. The medium was removed and $200 \mu \mathrm{l}$ dimethyl sulfoxide was added to each well. Absorbance (A) at $570 \mathrm{~nm}$ was recorded following $30 \mathrm{~min}$ incubation at room temperature. The cell survival rate was calculated as follows: Cell survival rate $=\mathrm{A}_{\text {drug }} / \mathrm{A}_{\text {control }} \times 100$.

Apoptosis protein detection via western blot analysis. Experiments were conducted as described for $\mathrm{Cdc} 2$. Primary monoclonal antibodies against B-cell lymphoma 2 (Bcl-2) and Bcl-2-associated X (Bax) were utilised. Secondary antibodies were mouse and goat anti-rabbit IgG (both 1:2,000).

Flow cytometry. MG63, MG63-siRNA/Scramble and MG63-siRNA/Cdc2 were collected, washed twice with ice-cold PBS and then fixed in $75 \%$ ethanol overnight at $4^{\circ} \mathrm{C}$. Following centrifugation at 2,000 rpm for $5 \mathrm{~min}$, cell pellets were resuspended in PBS containing $0.1 \%$ Triton X-100 and $50 \mu \mathrm{g} / \mathrm{ml}$ RNase A. The cell samples were then stained with $50 \mathrm{mg} / \mathrm{l}$ propidium iodide for $30 \mathrm{~min}$ at $37^{\circ} \mathrm{C}$ in the dark prior to flow cytometry.

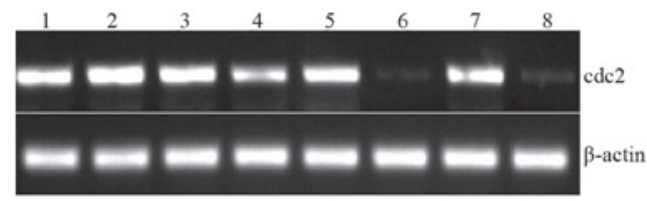

Figure 4. Cdc2 expression in six cloned strains was analysed by RT-PCR siRNA1-5 was identified to have the best silencing effect on Cdc2. Lane 1, MG63; 2, siRNA-Scramble; 3, siRNA1-1; 4, siRNA1-2; 5, siRNA1-3; 6, siRNA1-5; 7, siRNA1-7; 8, siRNA1-8. Cdc2, cyclin-dependent kinase 2; siRNA, small interfering RNA; RT-PCR, reverse-transcription polymerase chain reaction.

Statistical analysis. Data are expressed as mean \pm SD. Differences between two groups were analysed using the Student's t-test, whereas differences between three or more groups were analysed using ANOVA. $\mathrm{P}<0.05$ was considered to indicate a statistically significant difference.

\section{Results}

Plasmid construction. The siRNA-restructured plasmid was connected to psilencer 2.1-U6. The identity of the restructured plasmid psilencer 2.1/siRNA was confirmed via DNA sequencing (Fig. 1).

Cdc2 low-expression cell line. siRNA was transiently transfected into MG63 cells. Western blot analysis was then performed to determine the siRNA silencing efficiency (Fig. 2). siRNA-Scramble had no effect on Cdc2 expression and siRNA-1 exhibited higher silencing efficiency than siRNA-2. Therefore, siRNA-1 was used in the stable transfection. Western blot analysis and RT-PCR detected Cdc2 expression in six clones (Figs. 3 and 4). The siRNA1-5 clone exhibited the highest silencing efficiencies: 89 and $86 \%$ at the protein and mRNA levels, respectively. Immunofluorescence results demonstrated that, compared with normal MG63, MG63-siRNA/Cdc2 cells shrank and their structures changed into short, irregular, oblate spheroids. In addition, a reduced number of MG63-siRNA/Cdc2 cells were identified to express $\mathrm{Cdc} 2$ protein. No $\mathrm{Cdc} 2$ expression was observed in MG63-siRNA/Cdc2 cells.

MTT assay. The MTT assay detected MG63 cell proliferation following Cdc2 expression silencing (Fig. 5). Following culture for $24 \mathrm{~h}$, the growthrate of the MG63-siRNA/Cdc2 was identified as significantly lower than those of the MG63-siRNA/scramble and MG6 cells $(\mathrm{P}<0.01)$. These observations indicate that $\mathrm{Cdc} 2$ expression silencing inhibits cell proliferation. 
Table II. Effect of Cdc2-siRNA on the cell cycle in MG63 cells ( $\mathrm{n}=3)$.

\begin{tabular}{llll}
\hline & $\mathrm{G}_{0} / \mathrm{G}_{1}$ & $\mathrm{~S}$ & $\mathrm{G}_{2} / \mathrm{M}$ \\
\hline MG63 & $63.1 \pm 0.8$ & $25.0 \pm 0.7$ & $11.9 \pm 0.2$ \\
MG63-siRNA/Scramble & $62.8 \pm 0.9$ & $26.7 \pm 0.6$ & $10.5 \pm 0.2$ \\
MG63-siRNA/Cdc2 & $66.8 \pm 0.7^{\mathrm{a}}$ & $11.8 \pm 0.4^{\mathrm{b}}$ & $21.4 \pm 0.3^{\mathrm{b}}$ \\
\hline
\end{tabular}

${ }^{\mathrm{a}} \mathrm{P}<0.05$ and ${ }^{\mathrm{b}} \mathrm{P}<0.01, \mathrm{MG} 63-\mathrm{SiRNA} / \mathrm{Cdc} 2$ vs. MG63-SiRNA/Scramble. MG63 vs. MG63-SiRNA/Scramble was not identified to be statistically significant. Data are presented as the mean $\pm \mathrm{SD}$. Cdc2, cyclin-dependent kinase 2; siRNA, small interfering RNA.

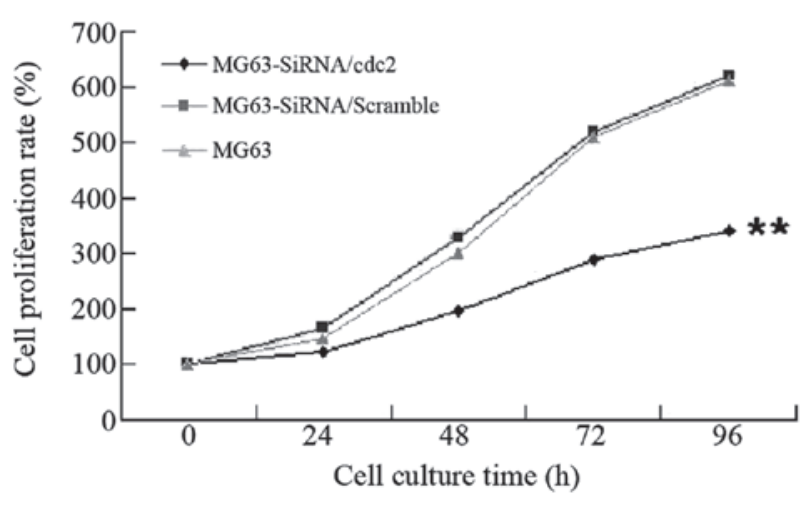

Figure 5. Effect of Cdc2 on proliferation of MG63 cells. Cdc2, cyclin-dependent kinase 2; siRNA, small interfering RNA.

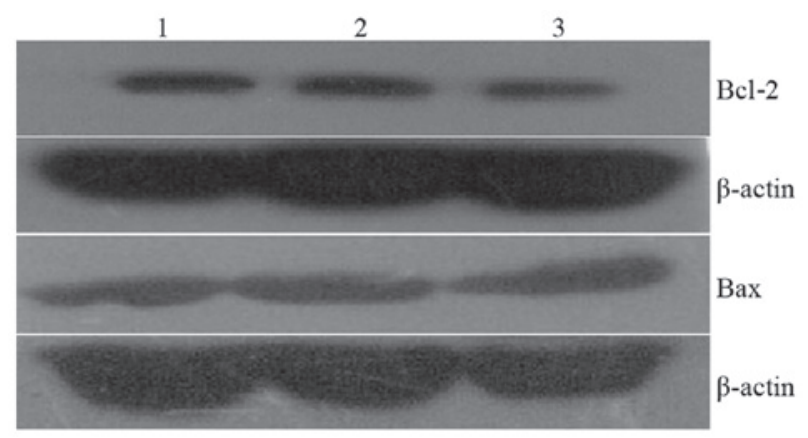

Figure 6. Expression of Bcl-2 and Bax in various MG63 cell groups $(n=3)$. Lane 1, MG63; 2, MG63-siRNA/Scramble; 3, MG63-siRNA/Cdc2. Cdc2, cyclin-dependent kinase 2; Bcl-2, B-cell lymphoma 2; Bax, Bcl-2-associated $\mathrm{X}$; siRNA, small interfering RNA.

Bcl-2, Bax gene expression. Bcl-2 expression in the MG63-siRNA/Cdc2 was not revealed to decrease significantly compared with the MG63-siRNA/scramble and MG63 cells $(126 \pm 16$ vs. $148 \pm 18,151 \pm 13$, respectively; $P>0.05)$. In addition, Bcl-2 expression in the MG63-siRNA/Cdc2 cells was not identified to increase significantly $(198 \pm 21$ vs. $186 \pm 26,178 \pm 25$, respectively; P>0.05; Fig. 6).

Cell cycle. Following $\mathrm{Cdc} 2$ expression silencing, MG63-siRNA/Cdc2 accumulated at the $\mathrm{G}_{2} / \mathrm{M}$ and $\mathrm{G}_{0} / \mathrm{G}_{1}$ phases compared with MG63-siRNA/scramble and MG63 cells. However, the number of MG63-siRNA/Cdc2 cells in the $\mathrm{S}$ phase was observed to be significantly reduced $(\mathrm{P}<0.05$; Table II).

\section{Discussion}

Osteosarcoma is the most common highly malignant tumour of the bone, often manifesting during the second or third decade of life. It accounts for $\sim 60 \%$ of all malignant bone tumours that occur during the first 20 years of life (8). The development of neoadjuvant chemotherapy has increased long-term survival rates from 10-20 to 60-70\%. However, although adjuvant chemotherapy effectively improves patient survival, as well as the treatment of primary tumours (9), patients who present with metastatic disease and/or tumour relapse remain associated with a poor prognosis. The estimated five-year survival rate following relapse is only $25 \%$ (10). To date, gene therapy studies of osteosarcoma pathogenesis and progression, have investigated p53, ezrin and surivin (11-16). However, few studies have focused on the molecular mechanism of $\mathrm{Cdc} 2$ in osteosarcoma cells.

In the present study, siRNA interference technology was used to obtain a low-Cdc 2 expression cell line. The cell line was then used to study the effects of siRNA-induced interference of $\mathrm{Cdc} 2$ expression on the proliferation and apoptosis of osteosarcoma MG63 cells. Normal MG63 cells exhibit long shuttle-like or triangular structures. Following Cdc2 expression silencing, cells exhibited short, irregular, oblate shapes which accumulated easily. MTT results demonstrate that Cdc2 expression silencing inhibits cell proliferation by blocking the cell cycle at the $\mathrm{G}_{2} / \mathrm{M}$ phase. Expression of the apoptosis genes, Bcl-2 and Bax, was also analysed to determine the possible effects of $\mathrm{Cdc} 2$ expression silencing on cell apoptosis. Cdc2 expression silencing had no effect on Bcl-2 and Bax, indicating that $\mathrm{Cdc} 2$ silencing does not promote MG63 cell apoptosis. Results of the present study indicate that $\mathrm{Cdc} 2$ expression silencing in MG63 cells inhibits cell proliferation but does not promote cell apoptosis. However, we previously hypothesised that disruption of $\mathrm{Cdc} 2$ expression inhibits osteosarcoma MG63 cell proliferation and promotes apoptosis. The absence of an observable effect of Cdc2 expression silencing on the apoptosis of MG63 cells may be due to the large number of genes associated with the regulation of apoptosis of MG63 cells. Although Cdc2 expression in MG63 cells, itself a regulation mechanism, is silenced, additional genes may be activated to offset low $\mathrm{Cdc} 2$ expression. Therefore, cells do not undergo apoptosis when $\mathrm{Cdc} 2$ alone is silenced. Inhibition of cell proliferation by $\mathrm{Cdc} 2$ expression silencing is attributed to the association between $\mathrm{Cdc} 2$ and the eukaryotic cell division cycle gene CDC2, which codes for a serine/ threonine protein kinase with a molecular weight of 3,400 Da. 
Cdc2 enzyme activation is an indicator of cell division. Cdc2 is vital to cell cycle regulation, inducing DNA replication and cell mitosis (17-19). Overexpression of Cdc2 is associated with cell cycle progression disorders, including abnormal growth and cell differentiation, as well as malignant cell proliferation and tumour formation (20). A number of previous studies have reported overexpression of Cdc 2 in breast cancer (21,22), B-cell lymphoma (23), colon carcinoma (24), ovarian cancer (25) and glioma (7) cells, as well as a marked correlation with tumour stage, grade, relapse and prognosis. Results of the current study are consistent with these observations.

In the present study, the expression levels of Bax and Bcl-2 only were analysed to detect cell apoptosis. Therefore, additional data are required to verify these results. Future studies must include analyses using an anticancer drug. The effect of Cdc2 expression silencing on the strength of the anticancer drug activity may then be determined. Three cell lines will be implanted in mice to investigate the effect of $\mathrm{Cdc} 2$ expression silencing on tumour growth, transfer and prognosis in vivo.

\section{Acknowledgements}

The present study was supported by the Natural Science Foundation of Hubei Province (D20101206).

\section{References}

1. Picci P: Osteosarcoma (osteogenic sarcoma). Orphanet J Rare Dis 2: 6, 2007.

2. Chou AJ, Geller DS and Gorlick R: Therapy for osteosarcoma: where do we go from here? Paediatr Drugs 10: 315-327, 2008.

3. Tan ML, Choong PF and Dass CR: Osteosarcoma: Conventional treatment vs. gene therapy. Cancer Biol Ther 8: 106-117, 2009.

4. Broadhead ML, Clark JC, Choong PF and Dass CR: Making gene therapy for osteosarcoma a reality. Expert Rev Anticancer Ther 10: 477-480, 2010

5. Li XZ, Meng L, Chen AM, Guo FJ, Luo ZQ and Zeng H: Screening of differentially expressed genes in osteosarcoma cell lines with various metastatic potentialities. Zhonghua Zhong Liu Za Zhi 1: 71-76, 2010 (In Chinese).

6. Li XZ, Meng L, Chen AM, Guo FJ, Luo ZQ and Zeng H: Differentially expressed gene in osteosarcoma cell lines with different metastatic potentials. J Nanjing Med Univ 23: 352-358, 2009.

7. Chen H, Huang Q, Dong J, Zhai DZ, Wang AD and Lan Q: Overexpression of $\mathrm{CDC} 2 / \mathrm{Cyclin} \mathrm{B} 1$ in gliomas, and CDC2 depletion inhibits proliferation of human glioma cells in vitro and in vivo. BMC Cancer 8: 29, 2008.
8. Winkler K, Beron G, Kotz R, et al: Neoadjuvant chemotherapy for osteogenic sarcoma: results of a Cooperative German/Austrian study. J Clin Oncol 2: 617-624, 1984.

9. Marina NM, Pratt CB, Rao BN, Shema SJ and Meyer WH: Improved prognosis of children with osteosarcoma metastatic to the lung(s) at the time of diagnosis. Cancer 70: 2722-2727, 1992.

10. Kempf-Bielack B, Bielack SS, Jürgens H, et al: Osteosarcoma relapse after combined modality therapy: an analysis of unselected patients in the Cooperative Osteosarcoma Study Group (COSS). J Clin Oncol 23: 559-568, 2005.

11. Oshima Y, Sasaki Y, Negishi H, et al: Antitumor effect of adenovirus-mediated p53 family gene transfer on osteosarcoma cell lines. Cancer Biol Ther 6: 1058-1066, 2007.

12. Walkley CR, Qudsi R, Sankaran VG, et al: Conditional mouse osteosarcoma, dependent on $\mathrm{p} 53$ loss and potentiated by loss of $\mathrm{Rb}$, mimics the human disease. Genes 22: 1662-1676, 2008.

13. Liang X, Da M, Zhuang Z, et al: Effects of Survivin on cell proliferation and apoptosis in MG-63 cells in vitro. Cell Biol Int 33: 119-124, 2009.

14. Wu YF, Liang XJ, Liu YY, et al: +Antisense oligonucleotide targeting survivin inhibits growth by inducing apoptosis in human osteosarcoma cells MG-63. Neoplasma 57: 501-506, 2010.

15. Kim C, Shin E, Hong S, et al: Clinical value of ezrin expression in primary osteosarcoma. Cancer Res Treat 41: 138-144, 2009.

16. Wang YF, Shen JN, Xie XB, Wang J and Huang G: Expression change of ezrin as a prognostic factor in primary osteosarcoma. Med Oncol 28 (Suppl 1): S636-S643, 2011.

17. Xu N and Chang DC: Different thresholds of MPF inactivation are responsible for controlling different mitotic events in mammalian cell division. Cell Cycle 6: 1639-1645, 2007.

18. Kim DH: Prognostic implications of cyclinB1, p34cdc2, $\mathrm{p} 27$ (Kip1) and p53 expression in gastric cancer. Yonsei Med J 48: 694-700, 2007.

19. Chang JT, Wang HM, Chang KW, et al: Identification of differentially expressed genes in oral squamous cell carcinoma (OSCC): overexpression of NPM, CDK1 and NDRG1 and underexpression of CHES1. Int J Cancer 114: 942-949, 2005.

20. Diril MK, Ratnacaram CK, Padmakumar VC, et al: Cyclin-dependent kinase $1(\mathrm{Cdk} 1)$ is essential for cell division and suppression of DNA re-replication but not for liver regeneration. Proc Natl Acad Sci USA 109: 3826-3831, 2012.

21. Kim SJ, Nakayama S, Miyoshi Y, et al: Determination of the specific activity of CDK1 and CDK2 as a novel prognostic indicator for early breast cancer. Ann Onco 19: 68-72, 2008.

22. Choi HJ and Zhu BT: Critical role of cyclin B1/Cdc2 up-regulation in the induction of mitotic prometaphase arrest in human breast cancer cells treated with 2-methoxyestradiol. Biochim Biophys Acta 1823: 1306-1315, 2012.

23. Zhao MY, Auerbach A, D'Costa AM, et al: Phosphop70S6K/p85S6K and cdc2/cdk1 are novel targets for diffuse large B-cell lymphoma combination therapy. Clin Cancer Res 15: 1708-1720, 2009 .

24. Meyer A, Merkel S, Brückl W, et al: Cdc2 as prognostic marker in stage UICC II colon carcinomas. Eur J Cancer 45: 1466-1473, 2009.

25. Shi HR and Zhang RT: Expression and significance of P53, P21WAF1 and CDK1 proteins in epithelial ovarian cancer. Ai Zheng 28: 882-885, 2009 (In Chinese). 